\title{
Combined DFT, Deconvolution Analysis for Structural Investigation of Copper -doped Lead Borate Glasses
}

\author{
A.M. Abdelghany* \\ Spectroscopy Department National Research Center, Dokki, Cairo, Egypt
}

\begin{abstract}
Samples from binary lead borate glass system doped with minor quantities of copper have been prepared by conventional melt-annealing technique. X-ray diffraction (XRD) has been used to prove the amorphous nature of prepared glasses. Structural and optical properties were investigated using FTIR and UV-vis. Spectroscopic investigations were approved using density function theory (DFT) calculations. Deconvolution analysis technique (DAT) combined with DFT technique were employed to interpret both of the theoretical and experimental IR data of this glass system and their agreement. Experimental IR data reveal the presence of both triangular and tetrahedral borate groups besides the sharing of $\mathrm{Pb}-\mathrm{O}$ units.

Direct and indirect optical energy band gaps before and after doping with different percents of copper were calculated to evaluate the role of copper in the glassy matrix. Undoped glass sample is observed to exhibit strong UV absorption due to the combined contributions of absorption of both $\mathrm{Pb}^{2+}$ ions and trace iron impurities. The presence of both $\mathrm{Cu}^{2+}$ ions together with the other copper valence state $\mathrm{Cu}^{+}$has been proved by the appearance of extra visible absorption bands.
\end{abstract}

Keywords: Lead borate glass, copper oxide, deconvolution analysis, FTIR, UV-Vis spectroscopy, DFT.

\section{INTRODUCTION}

Quantum mechanics can be used to study chemical processes such as those at the molecular level. Quantum chemistry uses a variety of approaches to approximate the solution of the Schrodinger equation for the system of interest. High level methods, both ab initio and density functional theory (DFT), work from first principles and generally take account of all the electrons in the system.

Density functional theory (DFT) has proven to be as a successful tool in condensed matter physics [1]. Hohenberg [2] proved that the ground state energy of any quantum mechanical system could be described as a functional of the one-body density only. Then, Fertig and Kohn [3] developed an orbital based method which could be applied to electronic systems. DFT methods are now generally accepted ways of going beyond semiempirical and ab initio Hartree Fock studies to include electron correlation effects without incurring the often unacceptable computational expense of ab initio methods beyond the Hartree Fock description, such as Moller Plessnet perturbation theory methods.

The problem of modeling of the condensed phases, such as glasses when using clusters of finite size, is that in order to preserve the correct valency, terminating groups or atoms need to be added to some atoms of the cluster. In the calculations described in this paper, clusters composed of different sizes of lead-borate rings and having different terminating groups have been proposed and studied using DFT method [1-3].

*Address correspondence to this author at the Spectroscopy Department National Research Center, Dokki, Cairo, Egypt; Tel: +2 0121133152;

Fax: +2 02 3370931; E-mail : a.m_abdelghany@yahoo.com
Over the full scale, quantitative IR spectroscopy comprises two stages of spectrum treatment implying a reconstruction of the spectra and the description of the spectrum under study in terms of individual band parameters

A number of studies have used curve-fitting technique to separate unresolved bands into several components $[4,5]$. In non-periodic or disordered systems, a distribution of individual geometries exists, which results in a distribution of vibrational wavenumbers. At the same time, a vibrational coupling with some degree of coherence between vibrating units is expected, which also affects the observed band shape in order that the fit be as realistic as possible.

In recent times, glasses based on heavy metal ions have received a great deal of attention due to their important optical applications $[6,7]$. Lead glasses are extensively used for various applications including decorative crystal glass and optical glasses, low-melting solder glasses and glassceramics, numerous optical and electronic applications, radiation protection and in immobilization of hazardous radioactive wastes $[8,9]$.

Borate glasses are one of the best glass forming system. It is often used as a dielectric and insulating material and it is known that lead borate glass is a good shield against gamma radiation. They are also of interest because of the occurrence of the boron anomaly leading to rich in glass chemistry [9].

Lead oxide is well known to show interesting behavior in the glass formation of many vitreous systems such as lead silicate, lead borate and lead phosphate glasses. The structural role of $\mathrm{Pb}^{2+}$ in the glass network has already been the subject of numerous studies [9-12]. In binary lead glasses, lead atoms are often described as glass formers at high lead content and as network modifiers at low lead content. Such 
differences in the structural role of $\mathrm{Pb}^{2+}$ ions would imply significant modifications of its local environment and of its coordination. Earlier studies $[10,11]$ consider that the glass forming groups in glasses containing $\mathrm{PbO}$ are the $\left[\mathrm{PbO}_{4}\right]$ units while recent studies [14] claim that $\mathrm{PbO}_{3}$ units or a mixture of the two $\left(\mathrm{PbO}_{4}, \mathrm{PbO}_{3}\right)$ groups are the basic building units.

In different glasses, copper can exist as a monovalent $\left(\mathrm{Cu}^{+}\right)$ion or as a divalent $\left(\mathrm{Cu}^{2+}\right)$ ion or containing both states and even metallic copper as in copper ruby glass. In a lead diborate glass matrix both $\mathrm{Cu}^{+}$and $\mathrm{Cu}^{2+}$ ions could be found [15]. Bright and prominent bluish green color could be attributed to the presence of $\mathrm{Cu}^{2+}$ ions from the point of view of ligand field theory [16]. The electronic structure of the copper atom is $[\mathrm{Ar}] 3 \mathrm{~d}^{10} 4 \mathrm{~s}^{1}$; and its stable ionic states are $\mathrm{Cu}^{+}$and $\mathrm{Cu}^{2+}$; the cuprous ion $\left(\mathrm{Cu}^{+}\right)$, having its five d-orbitals occupied, does not produce coloring [17], while $\mathrm{Cu}^{2+}$ ions create color centers with absorption bands in the visible wavelength region [16]; thus, producing attractive blue and sometimes green color to the materials. The color characteristics depend on the $\mathrm{Cu}^{2+}$ content, its specific coordination, composition and basicity of the glasses studied $[16,17]$. Recently, $\mathrm{Cu}^{2+}$ ions doped glasses have drawn a great attention because of their optical stability and variable optical and electrical applications [14-20].

The main objective of this present work is to understand the complex spectrum nature of conventional lead borate glassy materials in the $3 \mathrm{~B}_{2} \mathrm{O}_{3}-\mathrm{PbO}$ composition using combined DFT and deconvolution analysis methods. The effects of copper ions in the doping level used for improvement of optical and FTIR properties were also studied and discussed. This work will enable to specify the nature of copper ion valencies in such lead borate glass system.

\section{EXPERIMENTAL DETAILS}

\subsection{Preparation of Glasses}

The studied glasses were prepared using reagent grade chemical materials. $\mathrm{Pb}_{3} \mathrm{O}_{4}$ was used for $\mathrm{PbO}$ and $\mathrm{H}_{3} \mathrm{BO}_{3}$ for $\mathrm{B}_{2} \mathrm{O}_{3}$ and $\mathrm{CuO}$ was added as such with different successive percents as listed in Table 1. All the weighed batches were melted in platinum crucibles at $1000^{\circ} \mathrm{C}$ for $2 \mathrm{~h}$ and rotated several times to ensure complete melting, fining and homogeneity for prepared glass compositions. The homogenized melts were cast into slightly preheated stainless steel molds to the required dimensions and the prepared specimens were immediately transferred for annealing in a muffle furnace adjusted at $380^{\circ} \mathrm{C}$. The muffle was left to cool after $1 \mathrm{~h}$ to room temperature at a rate of $20^{\circ} \mathrm{C} \mathrm{h}^{-1}$.

\subsection{Spectroscopic and Structural Measurements.}

The optical absorption spectra before and after doping were measured at room temperature in the range from 200 to

Table 1. Added Weight Percent of Copper to Batches

\begin{tabular}{|c|c|c|c|c|c|}
\hline Sample & S0 & S1 & S2 & S3 & S4 \\
\hline \hline Wt.\% (g) & 0 & 0.5 & 1 & 2 & 3 \\
\hline
\end{tabular}

$2500 \mathrm{~nm}$ using a computerized recording spectrophotometer (type JASCO corp., V-570, Rel-00, Japan). Polished samples of equal thickness $(2 \pm 0.1 \mathrm{~mm})$ were used in these measurements.

The infrared absorption spectra of the prepared samples were measured at room temperature in the range 4000$400 \mathrm{~cm}^{-1}$ using a recording FTIR spectrophotometer type Mattson 5000, USA with the $\mathrm{KBr}$ disc technique. The samples were pulverized into fine powder, and then mixed with potassium bromide powder with a weight ratio of 1:100. The mixture was subjected to a load of 5 tons $\mathrm{cm}^{-2}$ in an evocable die for 2 min to produce clear homogenous discs. The IR absorption spectra were measured immediately after preparing the discs to avoid moisture and water attack.

X-ray diffraction studies were carried out to confirm the amorphous nature of the glassy samples over all compositions. A Philips PW1710 diffractrometer was used during the investigations with $\mathrm{CuK}_{\alpha}$. Absence of crystallization peak in XRD data indicates that, the prepared samples are amorphous in nature.

\subsection{DFT and DAT of Prepared Glasses}

Modeling process was used for investigating atomic details of materials enabling to retrieve information inaccessible by many experimental techniques. The geometry optimization of the proposed model structure was carried out using density function theory (DFT). The DFT computations were performed using Becke3 -Lee-Yang-Parr (B3LYP) exchange-correlation functional in conjunction with a CEP$4 \mathrm{G} / \mathrm{ECP}$ basis set method using GAUSSIAN 03 program package [21]. It should be noticed that termination of bonds at the boundary was made using hydrogen atoms. Frequency calculations were performed to ensure that the stationary points were minima and to calculate infrared (IR) spectra. The obtained spectra were compared with the deconvoluted experimental spectra.

It is found profitable in the deconvolution analysis technique to use in the first stage a minimum number of bands corresponding to the number of distinct features observed in the experimental spectra such as resolved maxima and well developed shoulders. To improve the fit, in the second stage, weaker bands are added which obey the following criteria: (a) The IR spectrum reveals an asymmetric mode that is also present in the published Raman spectra. (b) To take into account the structural groups present in smaller quantities for a given composition but it may be present in large quantities for another composition

\section{RESULTS}

\subsection{FTIR Absorption Spectra of Prepared Glasses}

The FTIR absorption spectra of the base undoped lead borate glass together with that for samples doped by copper ions are illustrated in (Fig. 1). The overall spectrum consists of distinctive absorption bands centered in the mid region extending from 500 to $1750 \mathrm{~cm}^{-1}$. The IR spectrum shows two small kinks at about 460 and $580 \mathrm{~cm}^{-1}$, a medium band at about $680 \mathrm{~cm}^{-1}$ and followed by two prominent broad bands; the first is centered at about $980 \mathrm{~cm}^{-1}$ and reveals a peak at $1050 \mathrm{~cm}^{-1}$ and the second is centered at about 1350 


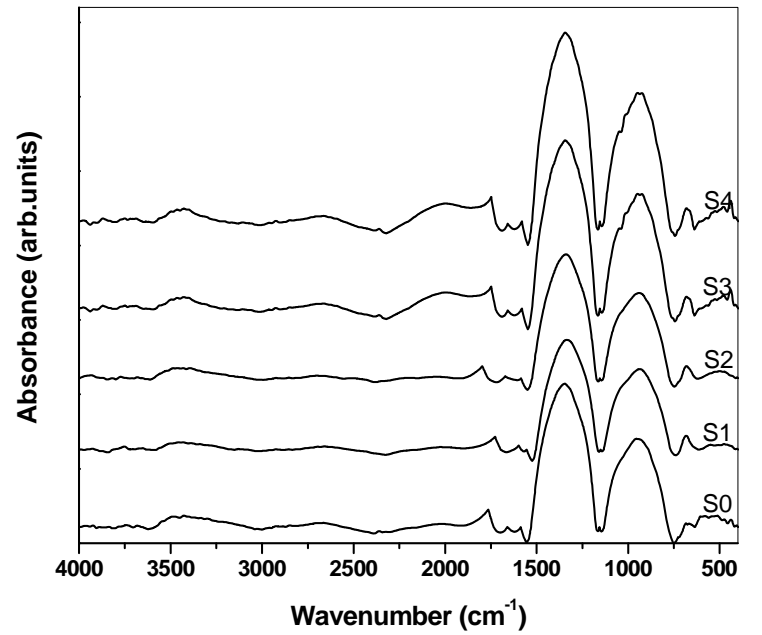

Fig. (1). IR absorption spectra of the prepared glasses before and after doping with $\mathrm{Cu}$.

$\mathrm{cm}^{-1}$. The IR spectrum also shows three small peaks at about 1560,1640 and $1950 \mathrm{~cm}^{-1}$. The rest of the spectrum reveals some small kinks at about 2880, 3680, 3750 and $3940 \mathrm{~cm}^{-1}$ together with a medium broad band with two peaks at about 3350 and $3480 \mathrm{~cm}^{-1}$. It is obvious that the main observed IR bands in the region $500-1600 \mathrm{~cm}^{-1}$ are related to borate network and the details of their assignments are given in Table 2 together with related references.

The optimized structure is shown in Fig. (2). The B-O bond length from $\left[\mathrm{BO}_{3}\right]$ triangular coordination and in

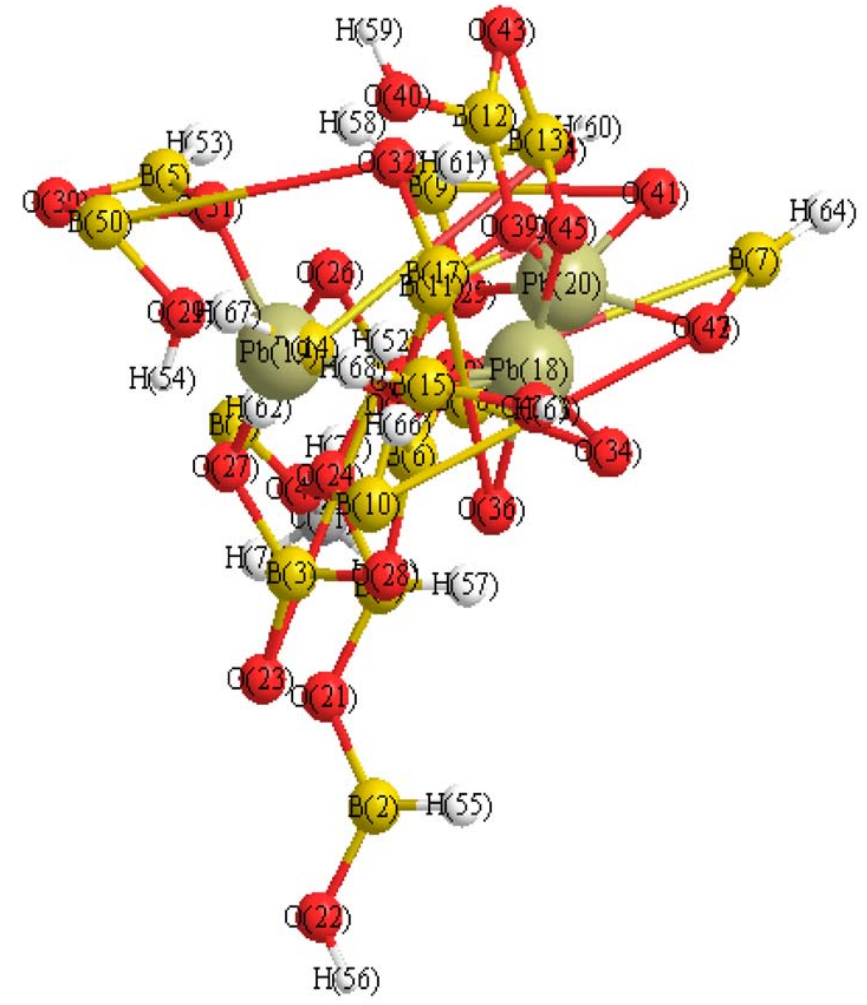

Fig. (2). The optimized structure of the probable model for the $3 \mathrm{~B}_{2} \mathrm{O}_{3}-\mathrm{PbO}$ glass system.
[BO4] tetrahedral units are in the same range (1.46-1.64 $\left.\mathrm{A}^{\circ}\right)$ as that of typical $\mathrm{B}-\mathrm{O}$ covalent bonds $\left(1.41 \mathrm{~A}^{\circ}\right.$ in $\left[\mathrm{BO}_{3}\right]$ units and $1.50 \mathrm{~A}^{\circ}$ in the tetrahedral $\left[\mathrm{BO}_{4}\right]$ units $[22]$ for crystalline compounds). In addition there are three $\mathrm{Pb}$ atoms in the proposed model is in a hexagonal coordination with oxygen atoms all are shorter than the ionic radii of $\mathrm{Pb}$ and $\mathrm{O}$ $\left(2.50 \mathrm{~A}^{\circ}\right)$ [23]. Taking into account all bonds, the average $\mathrm{Pb}-\mathrm{O}$ distance of $2.11 \mathrm{~A}^{\circ}$ is comparable to $\mathrm{Pb}-\mathrm{O}$ covalent bond distance of $2.20 \mathrm{~A}^{\circ}$ and the lead atom is strongly bonded to six oxygen atoms giving rise to a distorted octahedral arrangement which are in accordance with those found in other lead containing compounds whereupon adjacent borate layers are interconnected via ionic $\mathrm{Pb}-\mathrm{O}$ bonds and hydrogen bonding to form a 3D supramolecular network [24, 25].

Fig. (3a. b) shows the agreement of the calculated FTIR spectra obtained in the range $4000-400 \mathrm{~cm}^{-1}$ with the experimental results that obtained and analyzed using deconvolution analysis technique used for resolving overlapping peaks result from different vibration modes taking into account a small shift result from matrix effect.

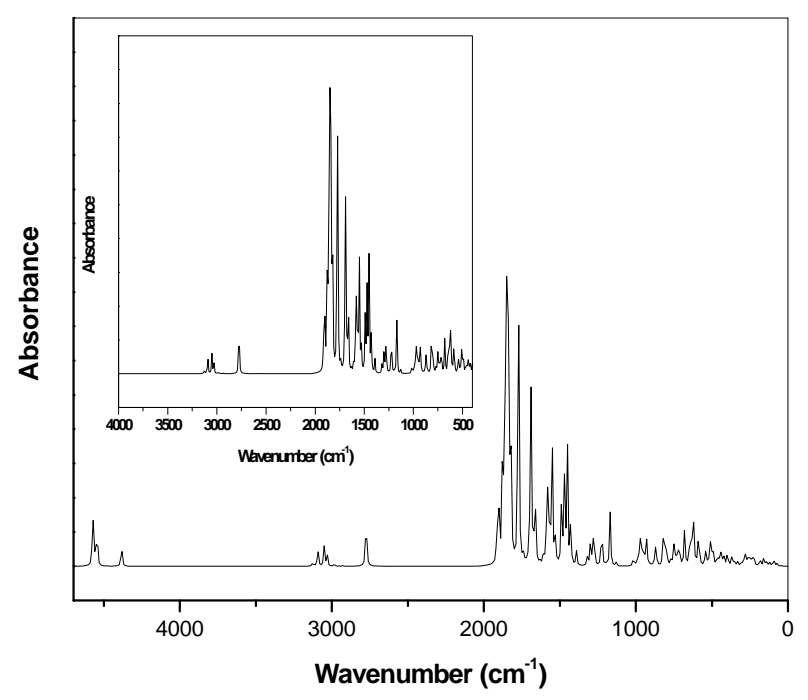

Fig. (3a). IR spectra obtained from DFT analysis.

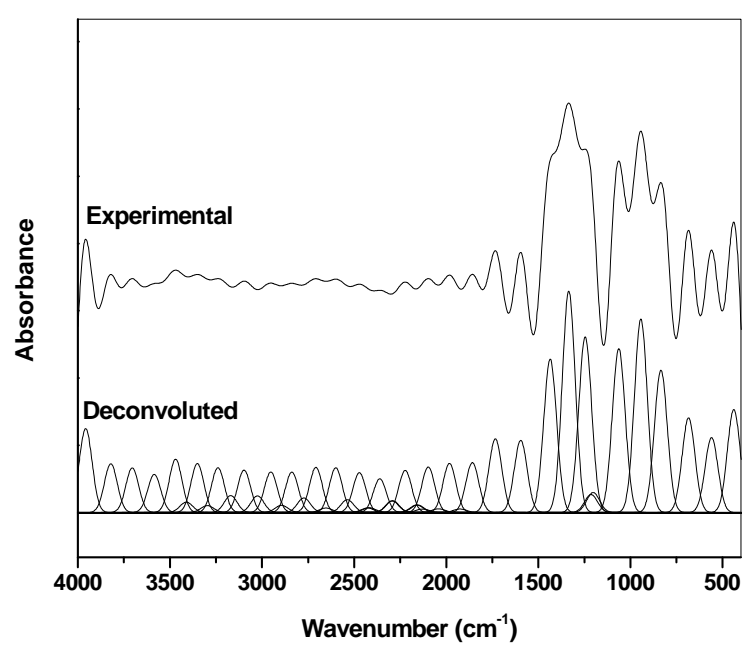

Fig. (3b). Experimental and deconvoluted IR spectral analysis. 
Table 2. Observed IR Vibrational Absorption Bands Wavenumber $\left(\mathrm{cm}^{-1}\right)$ and their Corresponding Vibrational Mode Assignments in the Undoped Lead Borate Glass Together with References

\begin{tabular}{|c|c|c|}
\hline Band position $\left(\mathbf{c m}^{-1}\right)$ & Associated vibrational mode & Ref. \\
\hline \hline $467,491,563,498,567$ & Loose $\mathrm{BO}_{4}$ units, $\mathrm{Pb}-\mathrm{O}$ vibrations & {$[4,13,20]$} \\
\hline 704,744 & B-O-B bending vibrations & {$[4,8,13]$} \\
\hline $912,960,972$ & B-O bond stretching of $\mathrm{BO}_{4}$ units with PbO bonds overlapping & {$[8]$} \\
\hline 1284,1288 & B-O stretching vibrations of $\left(\mathrm{BO}_{3}\right)^{3-}$ units in meta, orthoborate chains. & {$[4,8]$} \\
\hline 1300 & Vibrations of boron-oxygen rings & {$[8,20]$} \\
\hline $1505,1559,1611$ & Asymmetric stretching relaxation of the B-O bond of trigonal $\mathrm{BO}_{3}$ units. & {$[4,8,20]$} \\
\hline $1640,3446,3565,3747$ & Molecular water groups, BOH & {$[4,13]$} \\
\hline
\end{tabular}

\subsection{X-ray Diffraction Analysis}

Fig. (4) shows XRD spectra of the prepared undoped and doped glasses with different concentrations of copper which reveals no crystalline peaks indicating and confirming the amorphous structure of all samples with no change in its nature before and after successive addition of transition metal oxide $(\mathrm{CuO})$.

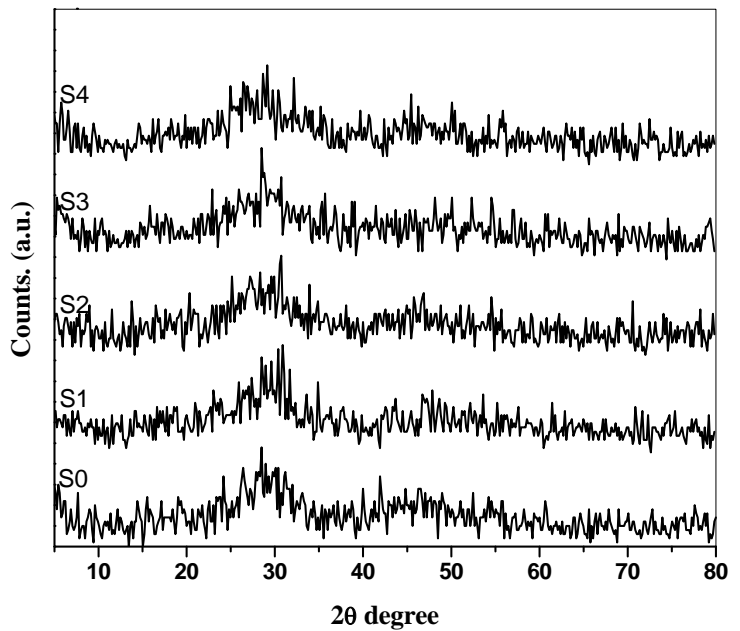

Fig. (4). XRD spectra of the prepared glasses before and after doping with $\mathrm{CuO}$.

\subsection{UV-visible Absorption Spectra}

Fig. (5) illustrates the optical absorption spectra of the undoped lead borate and $\mathrm{CuO}$-doped glasses. The optical spectrum of the base undoped lead borate glass shows strong ultraviolet absorption consisting of a broad band extending from 200 to about $420 \mathrm{~nm}$ with two peaks. The first is small at about 250 and the second is a prominent peak at $360 \mathrm{~nm}$, and no visible bands could be identified.

The CuO-doped glasses reveal extended UV-visible absorption spectra. The glass sample containing $0.5 \% \mathrm{CuO}$ shows a strong UV absorption band with three peaks at about 230, 280 and $380 \mathrm{~nm}$ followed by a very broad unsymmetrical visible band centered at about $740 \mathrm{~nm}$ and revealing a small kink at the descending lobe at about $875 \mathrm{~nm}$.

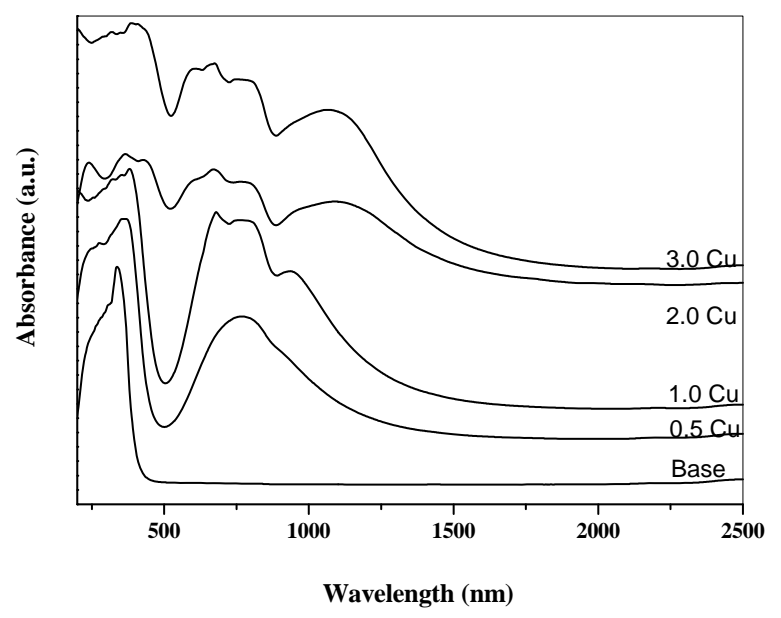

Fig. (5). Effect of dopant concentration on the UV-Vis. Spectra of lead borate glasses.

With glasses containing increasing $\mathrm{CuO}$ contents $(1,2$ and 3\%) the optical spectra of these glasses reveal strong ultraviolet absorption extending to near visible (200-500 nm) with small four peaks at about 250, 280, 350, $400 \mathrm{~nm}$ linked with two further visible absorption segments, the first part is broad consisting of four peaks at $600,710,790,850 \mathrm{~nm}$ and the second part consists of a broad band centered at about $1060 \mathrm{~nm}$.

\section{DISCUSSION}

\subsection{Interpretation of the Infrared Absorption Spectra}

Infrared spectra of vitreous and crystalline borates have been used as a basis for the qualitative identification of glass forming structural units in these glasses [4, 8, 26-28].

Due to structural disorder or non-periodic arrangement of the structural building units in glasses, a complete vibrational analysis in glasses is not possible. An analysis is done primarily by comparing the spectra of any specific glasses with those of corresponding crystalline borates for which the lattice structures are known.

Concerning the studied lead borate glass, it is considered to be an interesting system because lead oxide $(\mathrm{PbO})$, unlike alkali oxides, can enter the glass constitution both as network 
modifier and/or network former. Hence, the constitutional structure of the lead borate glass is expected to be different from that of alkali borate glasses.

Leventhal and Bray [10] have carried out NMR investigations of lead borate glasses and related compounds and their studies indicate that $\mathrm{N}_{4}$ (the fraction of the four coordinated boron atoms in the glass) increases with $\mathrm{PbO}$ content up to $50 \mathrm{~mol} \%$. Further increase of $\mathrm{PbO}$ decreases the value of $\mathrm{N}_{4}$ (ratio of $\mathrm{BO}_{4} / \mathrm{BO}_{3}$ ). The lead oxide is assumed to enter the glass network originally at $(0 \leq \mathrm{R} \leq 0.33)$ where $\mathrm{R}$ is the ratio of $\mathrm{PbO}$, it does so as a modifier [10]. In the case of $\mathrm{Pb}^{2+}$ ions, each ion acts as a dual charge balance providing the positive charge necessary for the formation of two tetrahedral borate $\left(\mathrm{BO}_{4}\right)^{-}$units. Beginning at $\mathrm{R}=0.33$, however, the role of cations begins to change. The lead ions are likely to form compact structural groups such as $\mathrm{PbO}_{4}$ and/or $\mathrm{PbO}_{3}$ pyramidal units taking on a more covalent arrangement. The participation of lead cations (and their associated oxygens) in these pyramidal units reduces the availability of such ions for ionic charge balance, thus reducing the formation rate of the four coordinated boron tetrahedral.

Careful inspection of the IR data shows that the two prominent broad bands at about 980 and $1350 \mathrm{~cm}^{-1}$ are not comparable or equivalent in intensity and the second band possesses higher intensity than the other first one. This means that the second IR band at $1350 \mathrm{~cm}^{-1}$ which is representing the vibrations of $\mathrm{BO}_{3}$ groups than the first band at $980 \mathrm{~cm}^{-1}$ which represents the vibrations of $\mathrm{BO}_{4}$ groups. In other words the IR data indicate that $\mathrm{BO}_{3}$ groups are present in amount more than $\mathrm{BO}_{4}$ groups. This experimental results comes in conformity with the studied base lead borate glass with the composition ( $\left.\mathrm{PbO} 70 \mathrm{wt} \%-\mathrm{B}_{2} \mathrm{O}_{3} 30 \mathrm{wt} \%\right)$. In accordance with the published work on borate glasses by various authors [4, 8, 29], the IR absorption in the region 800-1200 $\mathrm{cm}^{-1}$ can be assigned to $\mathrm{BO}_{4}$ groups while the absorption bands extending from $1200-1600 \mathrm{~cm}^{-1}$ can be related to $\mathrm{BO}_{3}$ groups.

Lead atoms occupies three different sites [30], the first is coordinated with six oxygen atoms forming distorted octahedral geometries. The second lead atom has an octahedral oxygen environment and the five $\mathrm{Pb}-\mathrm{O}$ bonds are considered as participating in the metal coordination scheme [31,32]. The third lead atom has ionic character. These sites cause the structural change from the continuous borate network to the continuous lead-borate network interconnected through $\mathrm{Pb}-$ $\mathrm{O}-\mathrm{B}$ and $\mathrm{B}-\mathrm{O}-\mathrm{B}$ bridges.

The calculated absorption spectrum of the proposed model is in good agreement with the experimental and deconvoluted IR absorption data.

\subsection{Interpretation of the UV-visible Absorption Spectra of CuO-doped Lead Borate Glasses.}

It is accepted that $\mathrm{Cu}^{2+}$ is the only known ion having the $3 \mathrm{~d}^{9}$ configuration [33]. The energy diagram for $\mathrm{d}^{9}$ systems in octahedral symmetry is just the inverse of that for octahedral $\mathrm{d}^{1}$ system. It is well known that the spectra of all glasses containing copper have at least a unique wide and asymmetrical broad visible band centered at $750-850 \mathrm{~nm}$ [34]. A comparison with the spectra of aqueous and crystalline cu- pric complexes shows that the $\mathrm{Cu}^{2+}$ ions must be present in the glass in approximately octahedral coordination [33, 34]. Duran et al. [17] have assumed that in $\mathrm{Cu}^{2+}$ chemistry there is no crystallographic evidence for a static regular octahedral stereochemistry whose lack of symmetry caused by an electronic hole in the $\mathrm{d}_{\mathrm{x}^{2}-\mathrm{y}} 2$ orbital produces the tetragonal distortion known as the Jahn-Teller effect. This effect causes, predominantly, an elongated octahedral stereochemistry with four short in-plane bond lengths and two longer axial bond lengths. This structure corresponds to a ligand field of $D_{\text {oh }}$ symmetry (tetragonal bipyramidal). Three absorption bands due to the transitions ${ }^{2} \mathrm{~B}_{1 \mathrm{~g}} \rightarrow{ }^{2} \mathrm{~B}_{2 \mathrm{~g}},{ }^{2} \mathrm{~B}_{1 \mathrm{~g}} \rightarrow{ }^{2} \mathrm{~A}_{1 \mathrm{~g}}$, and ${ }^{2} \mathrm{~B}_{1 \mathrm{~g}} \rightarrow$ ${ }^{2} \mathrm{E}_{\mathrm{g}}$ can appear in the visible and near infrared, their peak frequency depending on the distortion of regular environment. Duran et al. [17] have further assumed that the $\mathrm{Cu}^{2+}$ ions are coordinated by the nonbridging oxygens in silicate glasses and their influence become evident through the effect of alkali ions. Thus, the increasing distortion with change in chemical composition may thus be related to the change in polarizability of the oxygen ions surrounding the $\mathrm{Cu}^{2+}$ ions, and to its dependence on the field strength of the network former and modifier ions.

The broadness and asymmetry of the broad visible near IR band is believed to be due to splitting of a low-symmetry ligand-field component. Cozar and Aderlean [35] have called this local symmetry of $\mathrm{Cu}^{2+}$ as an unusual tetrahedral $\left(\mathrm{T}_{\mathrm{d}}\right)$ configuration.

On the basis of previous postulates, it is therefore assumed that the observed UV- near visible bands in the CuOdoped lead borate glasses are due to the combination of trace iron impurities and divalent lead $\mathrm{Pb}^{2+}$ ions while the visible bands are due to the presence of $\mathrm{Cu}^{2+}$ in distorted octahedral environment.

\section{CONCLUSIONS}

Homogeneous vitreous glasses from the $\left[3 \mathrm{~B}_{2} \mathrm{O}_{3}-\mathrm{PbO}\right]$ system were prepared and examined by means of XRD. FTIR spectroscopy has been used in order to analyze the local structural peculiarities of the vitreous samples, to identify the contributions of each component on the structure and to point out the role of the copper ions in the doping level as a modifier on the glass network.

Copper ions act as a color center effect in the electronic transition and modify structural units causing a change of boron coordination by means of conversion of $\left[\mathrm{BO}_{4}\right]$ to $\left[\mathrm{BO}_{3}\right]$ structural units.

Undoped lead borate glass exhibits broad UV absorption from collective combination of absorption due to trace iron impurities and divalent lead ions $\left(\mathrm{Pb}^{2+}\right)$. CuO-doped samples show the same UV as in the undoped glass but extending to $400 \mathrm{~nm}$ beside an additional wide broad visible band in the region 720-850 nm and with high $\mathrm{CuO}$ contents reveal extended and split very broad visible band with five peaks extending up to $1050 \mathrm{~nm}$.

Then, the observed and deconvoluted FTIR spectroscopic data were used in order to compute a possible model of glass matrix. The structural and vibrational properties of the proposed model of binary $3 \mathrm{~B}_{2} \mathrm{O}_{3}-\mathrm{PbO}$ glass network were determined by DFT calculations. Comparing the theoretical 
and experimental data, it is concluded that the method/basis sets used on the prediction of the structural data and vibrational modes is in agreement with proposed structure.

Lead atoms are accepted to be able to occupy three different sites, the first is coordinated with six oxygen atoms forming distorted octahedral geometries. The second lead atom has an octahedral oxygen environment and the five $\mathrm{Pb}-$ $\mathrm{O}$ bonds are considered as participating in the metal coordination scheme. The third lead atom has ionic character.

\section{ABBREVIATIONS}

$\begin{array}{lll}\text { DFT } & = & \text { Density function theory } \\ \text { DAT } & & \text { Deconvolution anlaysis techenique } \\ \text { IR } & \text { Infrared } \\ \text { FTIR }= & \text { Fourier transform infrared } \\ \text { XRD }= & \text { X-ray diffraction } \\ \text { NMR }= & \text { Nuclear magnetic resonance }\end{array}$

\section{ACKNOWLEDGEMENT}

Author would like to express his cordial thanks to Prof. Dr. M. A. A. Ibrahim for his valuable assistance during use of computer programs in his lab.

\section{CONFLICT OF INTEREST}

The author(s) confirm that this article content has no conflicts of interest.

\section{REFERENCES}

[1] Kohn W. Nobel lecture: Electronic structure of matter - Wave functions and density functional. Rev Mod Phys 1999; 71: 125366.

[2] Hohenberg PC. Colloquium: An introduction to consistent quantum theory. Phys Rev 2010; 82: 2835-44.

[3] Fertig HA, Kohn W. Symmetry of the atomic electron density in Hartree, Hartree-Fock, and density-functional theories. Phys Rev A 2000; 62: 052511-20.

[4] Kamitsos EI. Infrared studies of borate glasses. Phys Chem Glasses 2003; 44: 79-87.

[5] Abdelghany AM. The elusory role of low level doping transition metals in lead silicate glasses. Silicon 2010; 2: 179-84.

[6] Fu J. Lithium alkaline earth bismuthate glasses. Phys Chem Glasses 1996; 37: 84-6.

[7] Pan A, Ghosh A. A new family of lead-bismuthate glass with a large transmitting window. J Non-Cryst Solids 2000; 271: 157-61.

[8] Witke K, Harder U, Willfahrt M, Hubert T, Reich P. Vibrational spectroscopic investigations of lead borate and lead aluminoborate glasses. Glastech Ber Glass Sci Technol 1996; 69: 143-53.

[9] Chakradhar SRP, Murali A, Rao J, Ramakrishna LJ. Electron paramagnetic resonance and optical absorption studies of $\mathrm{Cu}^{2+}$ ions in alkali barium borate glasses. J Alloys Compd 1998; 265: 29-37.

[10] Leventhal M, Bray PJ. Nuclear magnetic resonance investigations of compounds and giasses in the sysbms $\mathrm{PbO}-\mathrm{B}_{2} \mathrm{O}_{3}$ and $\mathrm{PbO}-\mathrm{SiO}_{2}$. Phys Chem Glasses 1965; 6: 113-25.
[11] Meera N, Ramakrishna J. Raman spectral studies of borate glasses. J Non-Cryst Solids 1993; 159: 1-21.

[12] Akasaka Y, Yasui I, Nanba T. Network structure of $\mathrm{RO} \cdot 2 \mathrm{~B}_{2} \mathrm{O}_{3}$ glasses. Phys Chem Glasses 1993; 34: 232-7.

[13] Hubert T, Harder U, Mosel G, Witke K. Proc $2^{\text {nd }}$ Int Conf Borate glasses, crystals and melts, In: Wright AC, Feller SA, Hannon AC. Eds. Society of Glass Technology, Sheffield: UK 1997; pp. 156-63.

[14] Singh KJ, Singh N, Kaundal RS, Singh K. Gamma-ray shielding and structural properties of $\mathrm{PbO}-\mathrm{SiO}_{2}$ glasses. Nucl Instr Meth Phys Res B 2008; 266: 944-8.

[15] Ardelean I, Ilonca GH, Cozar O, Chicinaș I, Ciologria GH. Magnetic properties of $\mathrm{xCuO} \cdot(1-\mathrm{x})\left[2 \mathrm{~B}_{2} \mathrm{O}_{3} \cdot \mathrm{PbO}\right]$ glasses. SolidState Commun 1982; 43: 707-9.

[16] Bamford CR. The application of the ligand field theory to coloured glasses. Phys Chem Glasses 1962; 3: 189-202.

[17] Duran A, Navarro FJM. Colouring of glass by $\mathrm{Cu}^{2+}$ ions. Phys Chem Glasses 1985; 26: 126-31.

[18] Lakshminarayana $\mathrm{G}$, Buddhudu S. Spectral analysis of $\mathrm{Cu}^{2+}: \mathrm{B}_{2} \mathrm{O}_{3}$ ZnO-PbO glasses. Spectrochim Acta Part A 2005; 62: 364-71.

[19] Zhou Z, Navrotsky A, McClurem DS. Oxidation states of copper in lead borate glass. Phys Chem Glasses 1993; 34(6): 251-4.

[20] Thulasiramudu A, Buddhudu S. Optical characterization of $\mathrm{Cu}^{2+}$ ion-doped zinc lead borate glasses. J Quant Spectrosc Radiat Trans 2006; 97: 181-94.

[21] Rada S, Culea E, Rus V. Spectroscopic and quantum chemical investigation of the $4 \mathrm{Bi}_{2} \mathrm{O}_{3} \cdot \mathrm{B}_{2} \mathrm{O}_{3}$ glass structure. J Mater Sci 2008; 43 (10): 3713-6.

[22] Meera BN, Sood AK, Chandrabhas N, Ramakrishna J. Raman study of lead borate glasses. J Non-Cryst Solids 1990; 126: 224-30.

[23] Selvaraj U, Rao KJ. Role of lead in lead phosphomolybdate glasses and a model of structural units. J Non-Cryst Solids 1988; 104: 30015 .

[24] Krogh-Moe J, Wold-Hansen PS. The crystal structure of hexalead pentaborate, 6PbO. 5B $\mathrm{O}_{3}$. Acta Crystallogr 1973; B29: 2242-6.

[25] Ghoniem NA, ElBatal HA, Abdelghany MA, Ali IS. Shielding behavior of V2O5-Doped Lead Borate Glasses towards Gamma Irradiation. J Alloys Compd 2011; 509: 6913-9.

[26] Wright AC, Feller SA, Hannon AC, Eds. Proc $2^{\text {nd }}$ Int Conf Borate glasses crystals and melts. Society of Glass Technology Sheffield UK 1997.

[27] Dimitriev YB, Wright AC, Eds. Proc $3^{\text {rd }}$ Int Conf Borate glasses, crystals and melts, Society of Glass Technology, Sheffield: UK 2001.

[28] Pisarski WA, Pisarska J, Ryba-Romanowski W. Structural role of rare earth ions in lead borate glasses evidenced by infrared spectroscopy: BO3>BO4 conversion. J Mol Struct 2005; 744: 515-20.

[29] ElBatal FH, Azooz MA, Elkheshen AA. UV-visible and infrared spectra of gamma-irradiated transition metals-doped lead borate glasses. Trans Indian Ceram Soc 2009; 68(2): 81-90.

[30] Ispas S, Benoit M, Jund P, Jullien R. Structural and electronic properties of the sodium tetrasilicate glass $\mathrm{Na}_{2} \mathrm{Si}_{4} \mathrm{O}_{9}$ from classical and ab initio molecular dynamics simulations. Phys Rev B 2001; 64: 214206-61

[31] Corker DL, Glazer AM. The crystal structure and optical nonlinearity of $\mathrm{PbO} .2 \mathrm{~B}_{2} \mathrm{O}_{3}$. Acta Crystallogr 1996; B 52: 260-5.

[32] Wang GM, Sun YQ, Yang GY. Synthesis and characterization of a new layered lead borate. J Solid State Chem 2006; 179: 398-403.

[33] Bates T. Modern aspects of the vitreous state. In: Mackenzie JD, Ed. Butterworths: London 1962; vol. 2, p. 195.

[34] Bamford CR. Color generation and control in glass. Amesterdam: Elsevier Science Publishers 1977.

[35] Cozar O, Aderlean I. The local symmetry of $\mathrm{Cu}^{2+}$ ions in phosphate glasses. J Non-Cryst Solids 1987; 92: 278-81. 